\title{
Waste recycling in Malaysia: problems and prospects
}

\begin{abstract}
Recycling of solid wastes should be integrated into the existing and future waste management plans so as to yield the benefits of conservation of natural resources, saving of fossil fuels and prolonging lifespan times of disposal sites. This paper discusses the current status of waste recycling in Malaysia and its future prospects. Although a large amount of Malaysian wastes could be recycled, less than 5\% of the total (almost $10000 \mathrm{t} \mathrm{d}-1$ ) is actually separated and recycled. There is a good demand for waste plastics, paper and glass, with resale prices of about US\$60 t-1, US\$44 t-1 and US\$32 t-1, respectively. Recovery of only $5 \%$ of the available waste plastics, paper and glass is estimated to yield a total of about US\$3.4 million $\mathrm{y}-1$. Recommendations to increase recycling are discussed in the paper.
\end{abstract}

Keyword: Laws; Malaysia; Market prices; Policy; Scavengers; Scrap dealers; Solid waste recycling 